\title{
SARCOMA RETROPERITONEAL: RELATO DE CASO
}

\author{
Retroperitoneal sarcoma: case report
}

\section{Diego Henrique de Oliveira ${ }^{1}$ Flávia Medeiros Lima ${ }^{1}$ Arthur Ribeiro Ramos ${ }^{1}$ Gabriel Oliveira Leite de Oliveira ${ }^{2}$ Carlos Augusto Marques Batista ${ }^{2}$}

${ }^{1}$ Centro Universitário de Valença (UNIFAA) Valença (RJ)

${ }^{2}$ Hospital Escola de Valença - Valença (RJ)

Autor correspondente:

Flávia Medeiros Lima E-mail: flavialimmma1@gmail.com

\section{Como citar este artigo:}

OLIVEIRA, D.H.; LIMA, F.M.; RAMOS, A.R.; OLIVEIRA, G.O.L.; BATISTA, C.A.M. Sarcoma retroperitoneal: relato de caso. Revista Saber Digital, v. 14, n. 1, p. 32-38, 2021

Data de Submissão: 15/02/2021 Data de publicação: 03/05/2021

\section{RESUMO}

Introdução: O sarcoma retroperitoneal é um tumor maligno, raro, com origem na célula mesenquimal que sofre alteração em seu código genético, produzindo assim um tecido atípico. Normalmente é uma patologia assintomática até atingir um tamanho considerável de massa, na qual, seu crescimento é o principal fator causador de sintomas. A confirmação diagnóstica se dá através de exames de imagem somadas à biopsia e estudos anatomopatológicos. O tratamento de escolha é a cirurgia, aumentando a sobrevida do paciente acometido. Objetivo: divulgar um caso de sarcoma retroperitoneal em um paciente do Hospital Escola de Valença, com seu consequente desfecho, através da análise de prontuário e estudos em literatura. Relato de caso: Homem de 65 anos atendido no Hospital Escola de Valença apresentando dor lombar e hematúria, sendo identificada massa retroperitoneal com consequente ressecção da mesma e realização de estudos histológicos, evidenciando sarcoma de células fusiformes de alto grau. Conclusão: As lesões retroperitoneais são achados raros e representam um desafio terapêutico pois na maioria das vezes os pacientes se apresentam assintomáticos ou com sintomas inespecíficos.

Palavras-chave: tumor mesenquimal, malignidade, retroperitônio, cirurgia.

\section{ABSTRACT}

Introduction: Retroperitoneal sarcoma is a rare malignant tumor, originating in the mesenchymal cell that undergoes changes in its genetic code, thus producing atypical tissue. It is usually an asymptomatic pathology until it reaches a considerable size of mass, in which, its growth is the main factor causing symptoms. Diagnostic confirmation takes place through imaging tests in addition to biopsy and anatomopathological studies. The treatment of choice is surgery, increasing the survival of the affected patient. Objective: disclose a case of retroperitoneal sarcoma in a patient of the Hospital Escola de Valença, with its consequent outcome, through the analysis of medical records and studies in literature. Case report: 65-years-old man treated at the Hospital Escola de Valença presenting low back pain and hematuria, a retroperitoneal mass was identified with consequent resection and histological studies, showing high degree spindle cell sarcoma. Conclusion: Retroperitoneal lesions are rare findings and represent a therapeutic challenge because, in most cases, patients are asymptomatic or with non specific symptoms.
Keywords: mesenchymal
tumor, malignancy, 


\section{INTRODUÇÃO}

Os sarcomas retroperitoneais são tumores malignos que se originam a partir de células mesenquimatosas, localizadas no tecido adiposo, musculoesquelético e conjuntivo (MIGUEL,2011). São tumores raros, responsáveis por apenas 1 a $2 \%$ de todas as malignidades sólidas, das quais, cerca de 10 a 20\% são diagnosticados no retroperitônio. Quando levado em consideração apenas a região retroperitoneal o lipossarcoma é o tipo histológico mais frequentemente encontrado no Brasil (TONETO,2013).

No entanto, de todos os sarcomas, a maioria ocorre fora da região do retroperitônio e o pico de incidência se dá por volta da $5^{a}$ década de vida e com pequena preferência por mulheres brancas, porém pode ocorrer em qualquer faixa etária (TONETO,2013; WINDHAM,2005).

Esse tipo de tumor frequentemente é um achado acidental na investigação de sintomas ou doenças não relacionadas. Podem atingir tamanhos consideráveis antes de manifestar algum tipo de sinal ou sintoma, como, dor abdominal, lombalgias, obstruções intestinais ou massas palpáveis. Quando presentes, massa palpável e aumento de volume abdominal são os principais achados diagnósticos (TONETO,2013; TIU,2017).

Alguns fatores prognósticos observados são considerados importantes como rápido diagnóstico, tumor primário ressecável, baixo grau de malignidade, margens cirúrgicas livres, ausência de ruptura tumoral, ressecção em bloco e tratamento em centros de referência, sendo assim, associados a uma melhor sobrevida (MIGUEL,2011; LEWIS,1998).

A ressecção cirúrgica radical com margens livres é a única alternativa terapêutica com a possibilidade de obtenção de cura nesses pacientes, contudo, o atraso do diagnóstico, a dificuldade da sua localização e a invasão dos órgãos adjacentes, podem tornar o procedimento cirúrgico um desafio mesmo aos cirurgiões mais experientes (TONETO,2013).

Os métodos de imagens mais eficazes para o diagnostico são a tomografia computadorizada (TC) e a ressonância magnética (RNM), podendo 
auxiliar no estadiamento, diagnósticos diferenciais e definições estratégicas para a intervenção (WINDHAM,2005; STAWICKI,2017).

Este relato descreveu um paciente do sexo masculino de 65 anos diagnosticado com uma massa retroperitoneal com consequente ressecção da mesma e realização de estudos histológicos, no qual, foi diagnosticado como sarcoma de células fusiformes de alto grau no Hospital Escola de Valença (HEV).

\section{RELATO DE CASO}

Homem de 65 anos, hipertenso, deu entrada no Pronto Socorro do HEV apresentando dor lombar há 30 dias e hematúria há 4 dias, associado à palidez cutaneomucosa e perda ponderal de aproximadamente $10 \mathrm{Kg}$ em 3 meses.

Ultrassonografia de abdome total evidenciou lesão expansiva de $14 \mathrm{~cm}$ em rim esquerdo. TC de abdome e pelve com contraste evidenciou volumosa lesão expansiva, lobulada, com limites parcialmente definidos, com densidade de partes moles e impregnação heterogênea pelo contraste, medindo cerca de 12x13,6x12,8 cm, localizada em flanco esquerdo; a lesão era indissociável da borda anterior do rim esquerdo, da cauda pancreática e da parede posterior do cólon descendente/ângulo esplênico; além de tocar a borda inferior do baço e manter íntimo contato com hilo renal esquerdo (veia e artéria renais esquerdas).

Paciente foi submetido à laparotomia mediana, sendo encontrado: tumoração retroperitoneal em contato com cólon esquerdo, mesentério e rim esquerdo, medindo em conjunto $15 \times 13 \times 8 \mathrm{~cm}$; ao corte evidenciado massa tumoral volumosa, macia e brancacenta, com áreas esverdeadas e invasão de segmento intestinal. Realizada ressecção de massa tumoral e hemicolectomia esquerda com colostomia terminal de transverso.

Evoluiu no pós-operatório imediato na Unidade de Terapia Intensiva e sem intercorrências. Recebeu alta hospitalar nove dias após o procedimento cirúrgico, sendo encaminhado para seguimento ambulatorial, no qual apresentou boa evolução e colostomia funcionante. Paciente foi encaminhado para o Serviço 
de Oncologia Clínica sendo submetido a protocolo de quimioterapia, também sem intercorrências.

Estudo histopatológico evidenciou neoplasia fusocelularpleomórfica compatível com sarcoma pleommórfico de alto grau; alto índice mitótico, alto pleomorfismo, ausência de necrose e intestino com parede infiltrada até a mucosa. Foi solicitado estudo imuno-histoquímico para classificação da lesão, sendo classificada como sarcoma de células fusiformes de alto grau, do tipo lipossarcoma desdiferenciado.

Figuras 1 e 2 - TC de abdome e pelve com contraste.
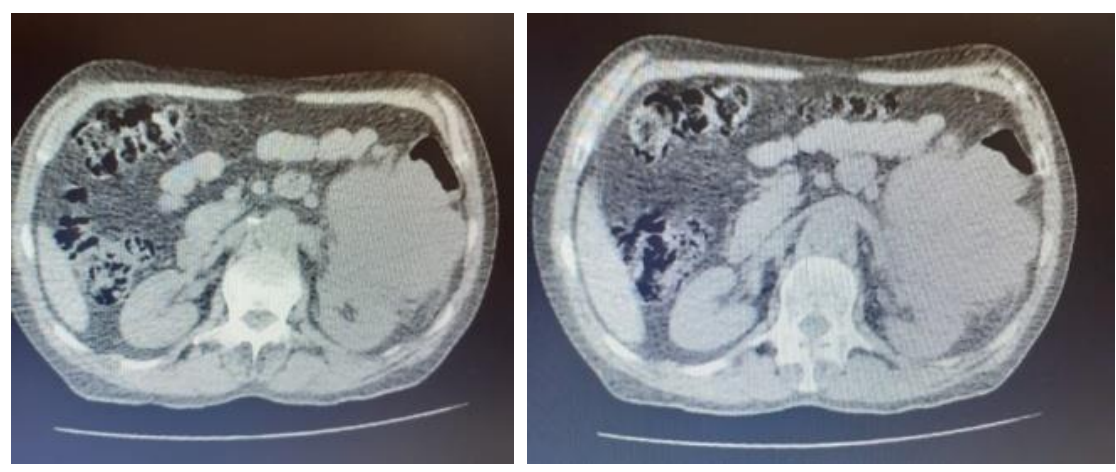

Figura 3 - Ato operatório: tumor retroperitoneal.

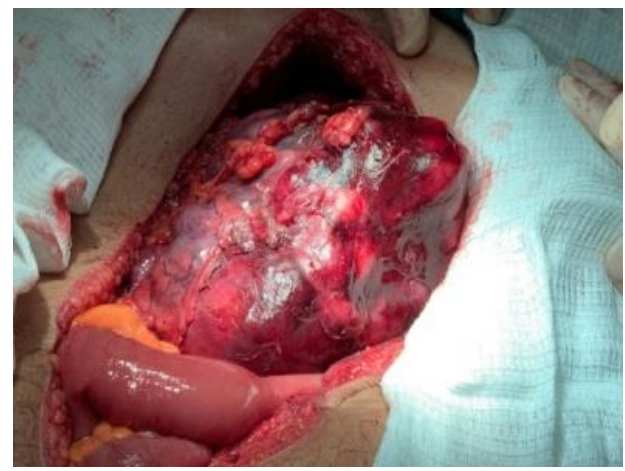


Figuras 4 e 5 - Peça operatória.
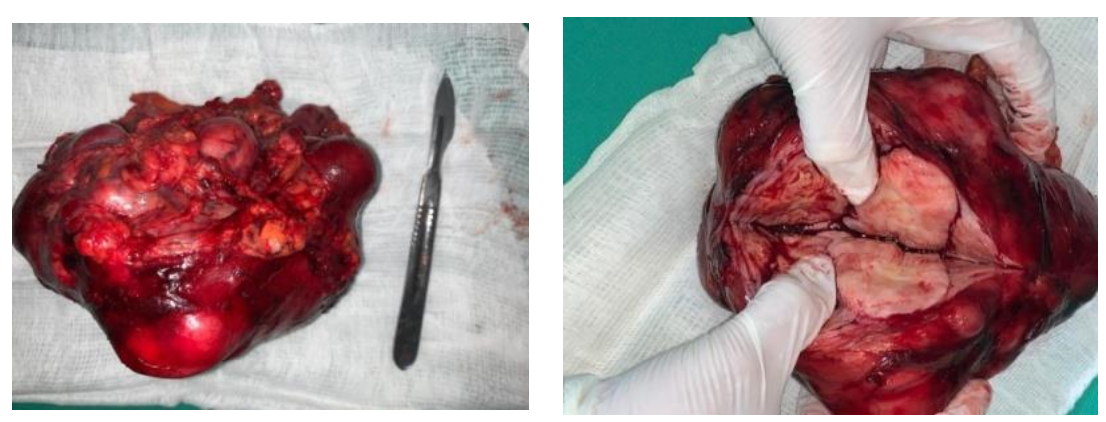

\section{DISCUSSÃO}

Sarcomas retroperitoneais possuem uma incidência baixa, representando cerca de 12 a $15 \%$ de todos os sarcomas de tecidos moles. Os subtipos de sarcomas mais frequentemente encontrados em adultos acima de 55 anos são lipossarcoma bem diferenciado, lipossarcoma desdiferenciado $(40 \%)$ e leiomiossarcoma (27\%). Normalmente são tumores malignos decorrentes das células mesenquimais, que estão localizadas nos tecidos musculares, adiposos ou conjuntivo (STAWICKI,2017; MESSIOU,2017).

Clinicamente apresentam-se, na maioria dos casos, de forma assintomática ou apenas como uma massa na região. Quando há presença de sintomas, estes são resultantes do efeito de massa ou da invasão local do tumor, tais como: oclusão gastrointestinal, dor em região lombar, edema de membros inferiores ou, até mesmo sintomas inespecíficos como perda de peso (MIGUEL,2011; STAWICKI,2017).A localização retroperitoneal implica em pior prognostico quando comparado ao lipossarcomas de extremidades, provavelmente devido à demora no diagnóstico e a localização anatômica complexa, que dificulta a ressecção com margens amplas e livres de tumor (TONETO,2013).

A TC é o principal teste inicial na avaliação de massas retroperitoneais primárias, fornecendo dicas muito úteis para o diagnostico final, facilitando a estimativa da localização da massa, seu tamanho, relação com órgãos 
circundantes e identificação de lesões metastáticas em fígado ou cavidade peritoneal, assim como a caracterização de possíveis tumores gordurosos (WINDHAM,2005; STAWICKI,2017; CHAUDHARI,2016).

A RM também pode fornecer informações úteis em relação à localização do tumor, envolvimento de estruturas circunvizinhas e presença de doença metastática, sendo também importante para avaliar órgãos específicos como pâncreas e glândulas adrenais, porém é uma técnica reservada para casos mais específicos (WINDHAM,2005; LEWIS,1998; STAWICKI,2017).

O tratamento de escolha é a cirurgia com ressecção total do tumor e estruturas ou órgãos adjacentes acometidos e garantindo de 50-60\% de taxa de sobrevida de 5 anos e de $49 \%$ de chance de recidiva. Não foi encontrado nenhum benefício na ressecção incompleta desses tumores, sendo esses pacientes expostos a morbidade do procedimento e não alcançando a potencial sobrevida que é o que se espera nos casos de pacientes submetidos a ressecção total do tumor. Devido ao não benefício das ressecções parciais, deve-se instituir o devido planejamento pré-operatório e buscando assim a completa remoção do tumor (MIGUEL,2011; WINDHAM,2005).

Quimioterapia e radioterapia sem a remoção cirúrgica, raramente têm sido benéficos, independente se combinados ou não, sendo por sua vez apenas indicadas em casos selecionados (BRENNAN,2014; MOTA,2018).

Portanto, deve-se instituir o follow-up frequente visto a grande taxa de recidiva tumoral, e nesses casos quando constatado recidiva local do tumor a indicação continua sendo a remoção cirúrgica sempre que possível (MIGUEL,2011).

\section{CONCLUSÃO}

As lesões retroperitoneais são achados raros e representam um desafio terapêutico devido à sua localização, tamanho, lesões em órgãos vizinhos e riscos de recidivas. Deve-se ter conhecimento e bom manuseio de exames de imagens para o auxílio no diagnóstico mais precoce e para o reconhecimento 
dos diagnósticos diferenciais, pois na maioria das vezes os pacientes se apresentam assintomáticos ou com sintomas inespecíficos.

\section{REFERÊNCIAS}

BRENNAN, Murray $F$. et al. Lessons learned from the study of 10,000 patients with soft tissue sarcoma. Annals of surgery, v. 260, n. 3, p. 416, 2014.

CHAUDHARI, Anantkumar et al. Evaluation of primary retroperitoneal masses by computed tomography scan. International Journal of Medical Science and Public Health, v. 5, n. 7, p. 1423-1430, 2016.

LEWIS, Jonathan J. et al. Retroperitoneal soft-tissue sarcoma: analysis of 500 patients treated and followed at a single institution. Annals of surgery, v. 228, n. 3, p. 355, 1998.

MESSIOU, C. et al. Primary retroperitoneal soft tissue sarcoma: imaging appearances, pitfalls and diagnostical go rithm. European Journal of Surgical Oncology (EJSO), v. 43, n. 7, p. 1191-1198, 2017.

MIGUEL, Isália et al. Sarcoma Retroperitoneal. Arquivos de Medicina, v. 25, n. 5-6, p. 180-182, 2011.

MOTA, Micaela Maciel dos Santos; BEZERRA, Regis Otaviano França; GARCIA, Marcio Ricardo Taveira. Abordagem prática de lesões retroperitoniais primárias no adulto. Radiologia Brasileira, v. 51, n. 6, p. 391-400, 2018.

STAWICKI, Stanislaw P. et al. Retroperitoneal sarcomas. International Journal of Academic Medicine, v. 3, n. 3, p. 44, 2017.

TIU, Andrew et al. Primary retroperitoneal mature cystic teratoma (dermoidcyst) in a 51-year-old male: case report and historical literature review. SAGE open medical case reports, v. 5, p. 2050313X17700745, 2017.

TONETO, Marcelo Garcia; DO CARMO LUCCHESE, Inara; REICHEL, Carlos Luiz. Lipossarcoma gigante de retroperitônio. Revista Brasileira de Cancerologia, v. 59, n. 2, p. 255-260, 2013.

WINDHAM, T. Christopher; PISTERS, Peter WT. Retroperitoneal sarcomas. Cancer control, v. 12, n. 1, p. 36-43, 2005. 